\title{
Based on the Growth Curve of Competitive Aerobics Athlete Athletic Abil- ity Development Research
}

\author{
Xiaona Yang ${ }^{1, *}$ and $\mathrm{Da} \mathrm{Ke}{ }^{2}$ \\ ${ }^{1}$ Wuhan Institute of Physical Education, Wuhan, Hubei, China $;{ }^{2}$ Institute of Physical Education, Central China Normal \\ University, Wuhan, Hubei, China
}

\begin{abstract}
Because of the competitive aerobics sports fun and keeping fit was deeply loved by the masses of young people, so the national fitness campaign project occupies a very important position, in order to improve the comprehensive performance of competitive aerobics players will be on the level of competitive aerobics athlete's physical stamina and skill in-depth analysis and research. Based on this the paper through the questionnaire survey, mathematical statistics method of competitive aerobics players, lifestyle, training time, frequency, etc were analyzed, and concluded that the competitive aerobics players to participate in a weekly exercise (57\%), showed that fewer training needs to be improved, $60 \%$ in 40 minutes of exercise time, training time arrangement in the afternoon, the optimal training standards which accord with human body. Then by using logistic growth curve method, fitness in one region predict the number of players, five years after 2014 young competitive aerobics players number, the number of middle-aged competitive aerobics players and the increased Numbers of older players of competitive aerobics, prove competitive aerobics a period of time in the future will be more and more popular.
\end{abstract}

Keywords: Competitive aerobics, growth curve, physiological indexes, sports ability.

\section{INTRODUCTION}

The middle of the last century began to widely circulated in the world of competitive aerobics, which is the United States and Japan respectively in 1983 and 1984, two successful hosting of the games competition, which laid a foundation for the rapid development of the competitive aerobics movement, with the improvement of people's living standard, competitive aerobics in expanding its influence on major sporting events, and received widespread praise [1].

About competitive aerobics predecessors have made a great contribution to the research, this paper first analyzes the basic situation of aerobics players [2, 3], to 2014 the number of China's competitive aerobics players change within five years is forecasted, and the rationalization of conclusions. The sustainable development of the research about the theory of competitive aerobics has the extremely important significance.

\section{MODEL ESTABLISHMENT}

Mathematical model is an important tool to solve practical problems, for competitive aerobics physical ability and technology research; we can analyze its data features through establishing mathematical model, and then predict Chinese competitive aerobics athletes' amount status [4].

Competitive aerobics is the foundation of Chinese sports development. Research on Chinese competitive aerobics female population activities ways, genders structure and experts evaluation, it will helpful for Chinese sports further development, and find problems and solve problems in constantly development.

Main factors that affect competitive aerobics performing contain body shape type, function type, psychology type, technique type and so on, as Table $\mathbf{1}$.

In order to further research competitive aerobics athletes development status, now make further statistics of their coaches' titles, and carry out comprehensive analysis, obtained result is as following Fig. (1) shows:

From the paper's competitive aerobics athletes multiple talents selection indicators and experts statistical graphs, it is clear that quality type occupies five items of multiple items, coaches occupies $60 \%$ of job titles in experts statistics [5].

By several days' interviewing and investigation, as well as going to Chinese competitive aerobics clubs, it makes concrete investigation and researches on professional competitive aerobics exercising status, list below Table $\mathbf{2}$.

In order to further analyze data features, now carry out statistical analysis, make research on Table 2 data, and draw following statistical figure:

Above Fig. (2) shows that experts think some of Chinese competitive aerobics clubs' professional competitive aerobics exercises status entirely is relative fit for their physical quality [6].

To do well in aerobics training cannot be realized in one day, carry out concreted contemporary investigation and 
Table 1. Multiple talents selection indicators.

\begin{tabular}{|c|c|c|}
\hline Type & Event & Number of Indicators \\
\hline \hline Psychology type & Standing stability and others & 3 \\
\hline Technique type & Comprehensive sports and others & 3 \\
\hline Body shape type & Height and others & 5 \\
\hline Function type & View and others & 6 \\
\hline Quality type & Cross jumping and others \\
\hline
\end{tabular}

Table 2. Statistical table of experts' evaluation on investigation status.

\begin{tabular}{|c|c|c|c|c|}
\hline Option & Very Suitable & More Suitable & General & Total \\
\hline \hline Frequency & 2 & 7 & 1 & 0 \\
\hline Proportion $(\%)$ & $20 \%$ & $70 \%$ & $10 \%$ & $0 \%$ \\
\hline
\end{tabular}

Fig. (1). Experts titles statistics.
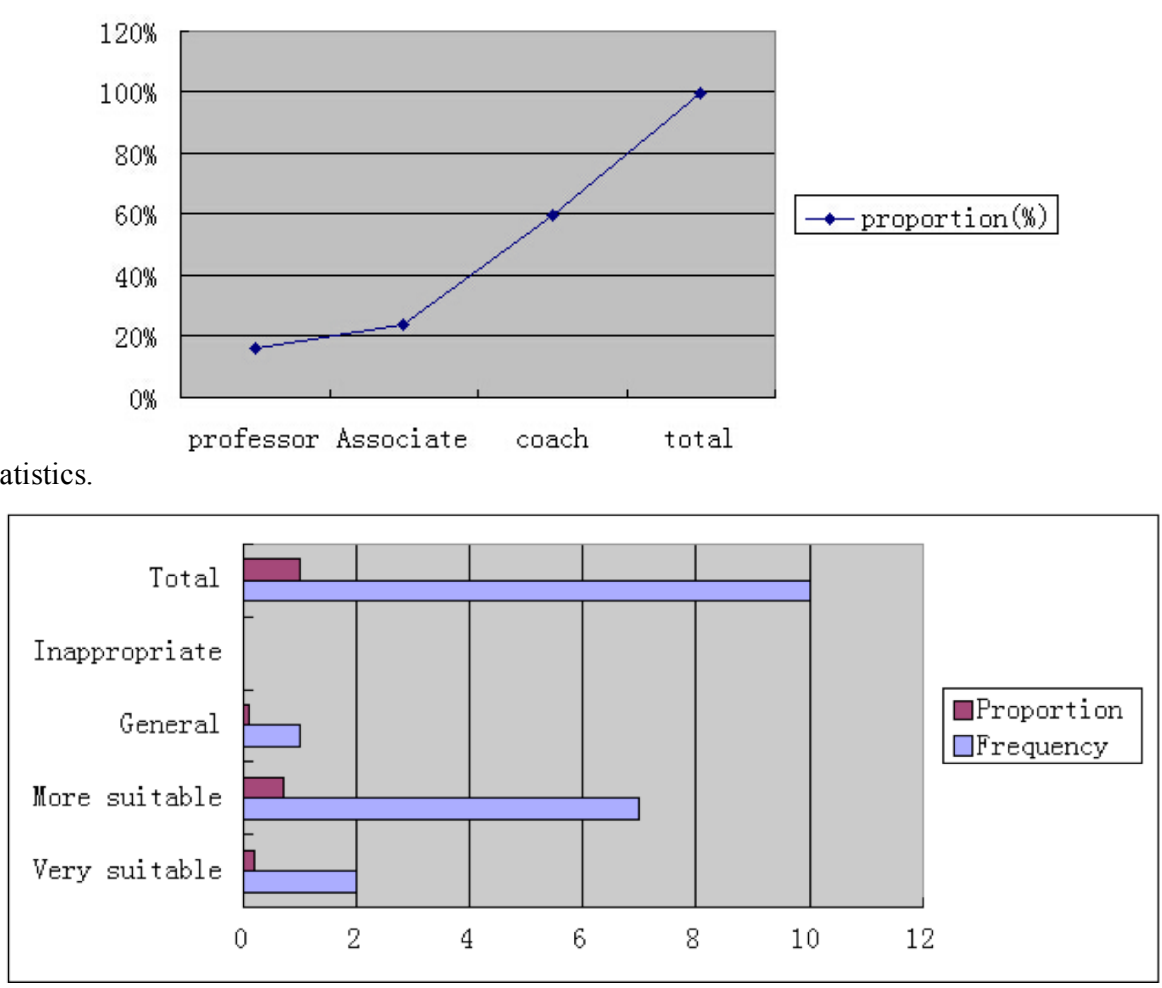

Fig. (2). Statistics experts to investigate the situation of the evaluation.

research on Chinese competitive aerobics training time and training contents as Table 3 [7-9].

To further analyze data features, now carry out statistical analysis, research on above Table $\mathbf{3}$ data, and draw following statistical Fig. (3).

In addition, the paper makes statistical analysis of aerobics athletes training time every time, and gets following Table 4 statistical results. To further analyze data features, now carry out statistical analysis, research on above table data, and draw following statistical Fig. (4).
In order to make reader more clear, the paper uses bar chart to make concrete analysis, researches on competitive aerobics physical training schedule, as following Fig. (5) shows:

The paper utilizes broken line figure, bar figure, scatter figure and other figures analysis, we can get that competitive aerobics athletes participate in one time training per week occupies $57 \%$ that shows training times are fewer that to be improved, training time around 40 minutes occupies $60 \%$, training time is arranged in the afternoon that conforms to body optimum training standard. 
Table 3. Statistics of number of physical training times per week.

\begin{tabular}{|c|c|c|c|c|}
\hline & 1 Time & 2 Times & 3 Times & Above 3 Times Sure \\
\hline \hline Selection times & 13 & 5 & 1 & 0 \\
\hline Proportion & $57 \%$ & $22 \%$ & $4 \%$ & 0 \\
\hline
\end{tabular}

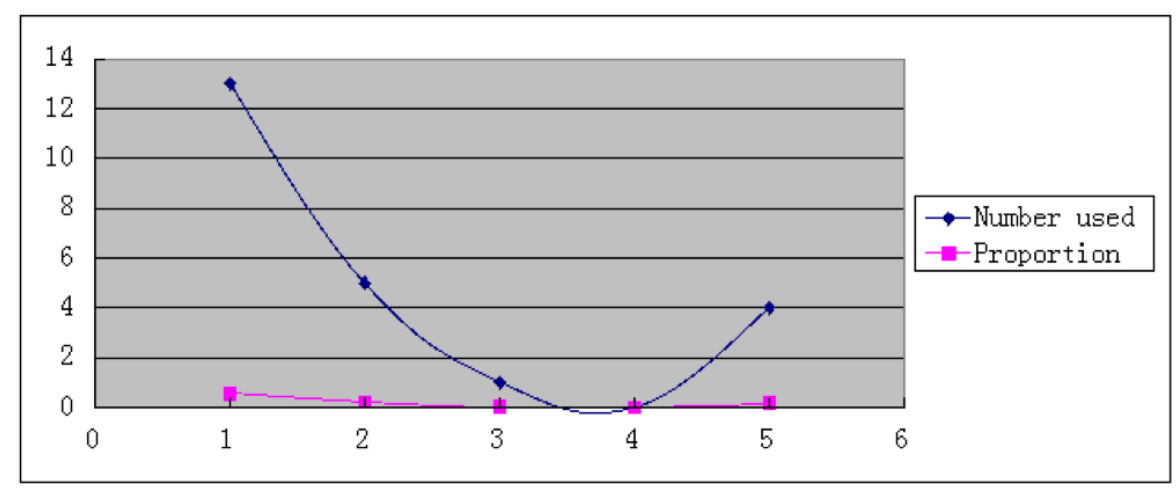

Fig. (3). Weekly physical training frequency statistics.

Table 4. Statistics of exercising time every time.

\begin{tabular}{|c|c|c|c|c|}
\hline & 20 Minutes & 40 Minutes & 80 Minutes & More \\
\hline Selection times & 2 & 15 & 7 & 1 \\
\hline Proportion & $8 \%$ & $60 \%$ & $28 \%$ & $4 \%$ \\
\hline
\end{tabular}

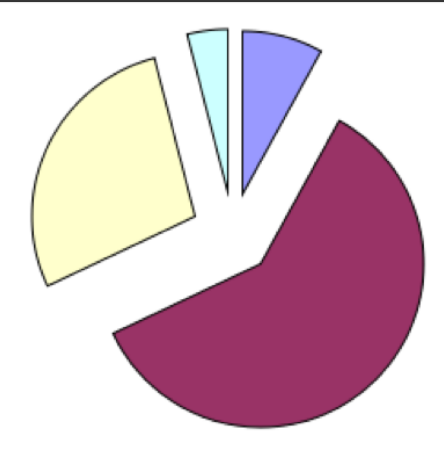

Fig. (4). Exercise time chart each time.

By Logistic growth curve method, predict year2015-2019 Chinese number of excellent competitive aerobics athletes and training techniques methods.

Things change rate is different in each period. Chinese sports system institution staff amount change trend is uncertain with time passing, here, introduce Logistic curve (growth curve), it has very wide application in such kind of uncertain development trend problems description.

Logistic curve general mathematical model is:

$$
\frac{d y}{d t}=r y\left(1-\frac{y}{L}\right)
$$

Among them, $y$ is predicted value, $L$ is its limit value, $r$ is growth constant, and $r>0$. Solve the differential equation, finally it gets:

$$
y=\frac{L}{1+c e^{-r t}}
$$

In the following, record Logistic curve general form as:

$$
y_{t}=\frac{1}{K+a b^{t}}, K>0, a>0,0<b \neq 1
$$

Among them, in Logistic curve, parameter estimation makes following changes: $Y_{t}^{\prime}=\frac{1}{Y_{t}}$, that: 


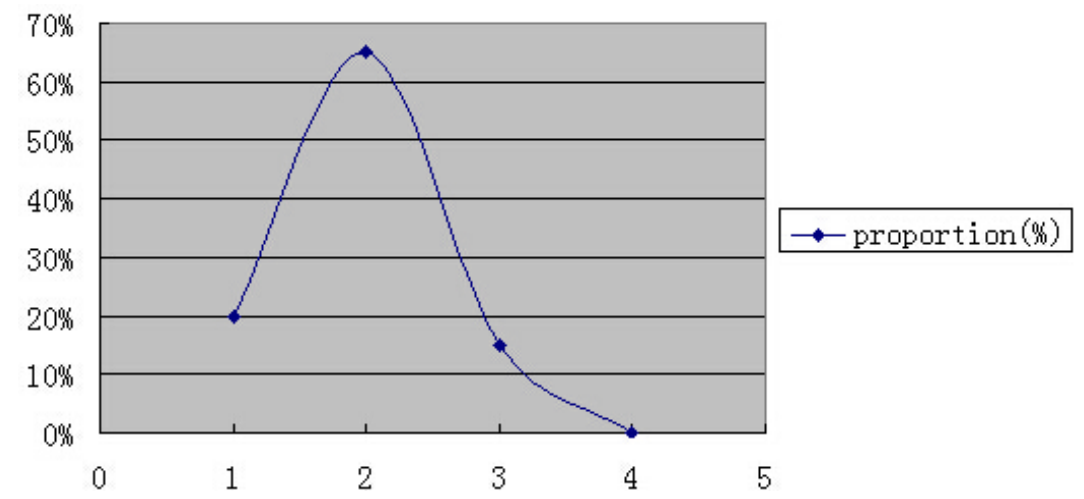

Fig. (5). For physical training schedule.

Table 5. Data table after logistic curve changing.

\begin{tabular}{|c|c|c|c|c|c|c|}
\hline \multirow{4}{*}{$\begin{array}{c}\text { Number of } \\
\text { people }\end{array}$} & Years & 2015 & 2016 & 2017 & 2018 & 2019 \\
\hline & Competitive aerobics young athletes & 3479 & 3798 & 3981 & 4149 & 4596 \\
\hline & Competitive aerobics middle-aged athletes & 1241 & 1377 & 1638 & 1828 & 2292 \\
\hline & Competitive aerobics senior athletes & 129 & 138 & 151 & 189 & 199 \\
\hline
\end{tabular}

$y_{t}^{\prime}=K+a b^{t}$

For time sequence $n$ pieces of corresponding observation value average divided three parts, and for every part, it has $m$ periods, and then it has $n=3 m$.

Part one: $y_{1}, y_{2}, y_{3}, \cdots, y_{m}$;

Part two: $y_{m+1}, y_{m+2}, y_{m+3}, \cdots, y_{2 m}$;

Part three: $y_{2 m+1}, y_{2 m+2}, y_{2 m+3}, \cdots, y_{3 m}$

Among them, every part trend sum is equal to corresponding observation values sum, therefore provide parameters estimation, three sums method steps are as following:

Record observation values each part sum is :

$S_{1}=\sum_{t=1}^{m} y_{t}^{\prime}, S_{2}=\sum_{t=m+1}^{2 m} y_{t}^{\prime}, S_{3}=\sum_{t=2 m+1}^{3 m} y_{t}^{\prime}$,

And it has:

$$
\left\{\begin{array}{l}
S_{1}=\sum_{t=1}^{m} \hat{y}_{t}=\sum_{t=1}^{m}\left(K+a b^{t}\right)=m K+a b\left(1+b+b^{2}+\cdots+b^{m-1}\right) \\
S_{2}=\sum_{t=m+1}^{2 m} \hat{y}_{t}=\sum_{t=m+1}^{2 m}\left(K+a b^{t}\right)=m K+a b^{m+1}\left(1+b+b^{2}+\cdots+b^{m-1}\right) \\
S_{3}=\sum_{t=2 m+1}^{3 m} \hat{y}_{t}=\sum_{t=2 m+1}^{3 m}\left(K+a b^{t}\right)=m K+a b^{2 m+1}\left(1+b+b^{2}+\cdots+b^{m-1}\right)
\end{array}\right.
$$

Among them: $\left(1+b+b^{2}+\cdots+b^{m-1}\right)(b-1)=b^{m}-1$

And then it can get:

$$
\left\{\begin{array}{l}
S_{1}=m K+a b \frac{b^{m-1}}{b-1} \\
S_{2}=m K+a b^{m+1} \frac{b^{m-1}}{b-1} \\
S_{3}=m K+a b^{2 m+1} \frac{b^{m-1}}{b-1}
\end{array}\right.
$$

Therefore, it can get:

$$
\left\{\begin{array}{l}
b=\left(\frac{S_{3}-S_{2}}{S_{2}-S_{1}}\right)^{\frac{1}{m}} \\
a=\left(S_{2}-S_{1}\right) \frac{b-1}{b\left(b^{m}-1\right)^{2}} \\
K=\frac{1}{m}\left[S_{1}-\frac{a b\left(b^{m}-1\right)}{(b-1)}\right]
\end{array}\right.
$$

Besides, when predict data, it should test data, test method is:

$$
\frac{y_{t+1}-y_{t}}{y_{t}-y_{t-1}} \approx b
$$

By $y_{t}^{\prime}=\frac{1}{y_{t}}$, it gets after changing year 2014 2019 data is as following Table $\mathbf{5}$.

According to formula (5), it gets:

$S_{1}^{1}=0.682, S_{2}^{1}=0.614, S^{1}{ }_{3}=0.377$

Then by formula (8), it gets:

$b^{1}=1.867, a^{1}=-0.005111, K^{1}=0.35468$ 


$$
b^{2}=1.6999, a^{2}=-0.0001453, K^{2}=0.1281
$$

So obtained competitive aerobics system institution staff amount logistic growth curve mathematical model is:

$$
\left\{\begin{array}{l}
y^{1}{ }_{t}=\frac{1}{0.35468-0.00511 \times 1.867^{t}} \\
y^{2}{ }_{t}=\frac{1}{0.1281-0.0001453 \times 1.6999^{t}} \\
y^{3}{ }_{t}=\frac{1}{0.0748+0.000796 \times 1.5128^{t}}
\end{array}\right.
$$

When predicting one region competitive aerobics systematic institution staff development changes in future five years after 2013, only need to input $t$ value into above formula, as predict $y_{2013}$, then it has $t=2013-2004+1=10$.

By above calculation result analysis, it gets conclusions: one region number of young competitive aerobics athletes, number of middle-aged competitive aerobics athletes and number of the senior competitive aerobics athletes have increased in five years after 2014, they are in the rising trend, indicates that Chinese competitive aerobics achieve certain effects in reformation, but Chinese person-time total amount is still smaller that to be further improved.

\section{CONCLUSION}

(1) This paper analyzes the present situation of the competitive aerobics, by using the questionnaire survey, mathematical statistics method of competitive aerobics players, lifestyle, training time, frequency, etc were analyzed, and concluded that the competitive aerobics players to participate in a weekly exercise $(57 \%)$, showed that fewer training needs to be improved, $60 \%$ in 40 minutes of exercise time, training time arrangement in the afternoon, the optimum training standards accord with human body.

(2) In addition to competitive aerobics exercise, exercise time as well as the choice of the time period studied, $70 \%$ of the experts think the more appropriate, that China's competitive aerobics cause effect is significant, the direction of reform for the future development of China's competitive aerobics cause provide a good space for development;
(3) At the end of the paper, by using logistic growth curve method, the number of fit players predicts in one region, it is concluded that in the next five years, 2015-2019, the number of youth players of competitive aerobics, the number of middle-aged competitive aerobics players and the number of elderly competitive aerobics players has increased the number of competitive aerobics players presents a gradually increasing trend, prove that a period of time in the future development of competitive aerobics will be more and more brilliant.

\section{CONFLICT OF INTEREST}

The authors confirm that this article content has no conflict of interest.

\section{ACKNOWLEDGEMENTS}

Declared none.

\section{REFERENCES}

[1] L. Qingqing, "Pondering Over about the callisthenic teaching of the ordinary colleges and universities,"Sports Science Research, vol. 11, no. 8, pp. 112-119,1998

[2] D. Dong-sheng,"State Investigation and countermeasure analysis on aerobics teaching to art major students of the art college,"Fujian Sports Science and Technology, vol. 27, no. 1, pp. 51-53, 2008.

[3] Y. Ji-ping, and R. Meng-hua, "A Study on the teaching pattern of callisthenics,"Journal of Physical Education Institute of Shanxi Teachers University, vol. 18, no. 4, pp. 47-49, 101, 2003,

[4] G. Gai-ling,"Research on the effects of callisthenics on the physical quality of the college girl students,"Journal of Physical Education Institute of Shanxi Teachers University, vol. 17, no. 4, pp. 41-42, 2002.

[5] L. Jie, and L. Hui-jun, "On the Teachers"'" "Education" of Callisthenics in Colleges and Universities,"Journal of Liuzhou Teachers College, vol. 20, no. 4, pp. 84-85, 130, 2005.

[6] L. Xiu_hua, L. Cheng, and Y. Xiao_hong, "The reform of callisthenic examination methods in university,"Journal of Guangzhou Physical Education Institute, vol. 21, no. 4, pp. 107-109, 2001.

[7] W. Jie-feng, "Problems and Solutions: On Bilingual Teaching in Colleges and Universities,"Journal of Fuyang Teachers College (Social Science Edition), vol. 1, pp. 146-148, 2010.

[8] W. Jinfang, "On the development trend or popular callisthenics, "Journal of Hubei Sports Science, vol. 1, pp. 201-222, 1997.

[9] L. Lin, "On quality education and the improvement of teaching method of areobics dancing, Journal of Guangzhou Physical Education Institute, vol. 21, no. 4, pp.110-112, 2001.

\begin{tabular}{lcc}
\hline Received: June 10, 2015 & Revised: July 29, 2015 & Accepted: August 15, 2015 \\
C) Yang and Ke; Licensee Bentham Open. &
\end{tabular}

This is an open access article licensed under the terms of the (https://creativecommons.org/licenses/by/4.0/legalcode), which permits unrestricted, noncommercial use, distribution and reproduction in any medium, provided the work is properly cited. 